\title{
Indicadores para estimativa da digestibilidade parcial em bovinos ${ }^{1}$
}

\section{Marcia Dias $^{2}$, Edenio Detmann ${ }^{3^{*}}$, Maria Ignez Leão ${ }^{3^{*}}$, Shirley Motta de Souza ${ }^{4}$, Sebastião de Campos Valadares Filho ${ }^{3^{*}}$, Angela Maria de Vasconcelos ${ }^{5}$, Luciana Navajas Rennó ${ }^{6}$, Rilene Ferreira Diniz Valadares ${ }^{7^{\star}}$}

\author{
1 Parte da dissertação de Mestrado da primeira autora, financiada pelo CNPq. \\ 2 Doutoranda em Zootecnia - UFV. \\ ${ }^{3}$ Departamento de Zootecnia - UFV. \\ ${ }^{4}$ Mestranda em Zootecnia - UFV. \\ 5 UVA. \\ 6 UNIPAC \\ 7 Departamento de Veterinária - UFV. \\ * Bolsista do CNPq.
}

RESUMO - Objetivou-se avaliar a digestibilidade intestinal da FDN estimada por diferentes indicadores e o efeito das amostras coletadas no período diurno ou diário sobre a digestibilidade desse nutriente. Utilizaram-se quatro novilhas Holandês-Zebu, fistuladas no rúmen e no íleo, mantidas em regime de confinamento com dieta à base de feno de capim-tifton (Cynodon spp.), oferecido ad libitum, e $1 \mathrm{~kg}$ de concentrado (27\% PB). O experimento durou 60 dias divididos em três períodos de 15 dias. A adaptação à dieta experimental foi de sete dias e, entre os períodos, respeitou-se um intervalo de quatro dias.

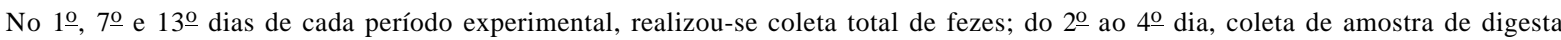
omasal e, do 8 o ao 10 o dia, amostras de digesta ileal. Para a mensuração do fluxo de digesta omasal, foram utilizados os sistemas de indicadores único e duplo. No sistema único, foram comparados a fibra em detergente neutro indigestível (FDNi), a fibra em detergente ácido indigestível (FDAi) e o óxido crômico $\left(\mathrm{Cr}_{2} \mathrm{O}_{3}\right)$. No sistema duplo, foram comparadas as associações entre o complexo de cobalto-ácido etilenodiaminotetracético (Co-EDTA) com a FDNi (Co-FDNi) e a FDAi (Co-FDAi). Para estimativa do fluxo ileal, foram utilizados apenas os indicadores únicos. Não foi verificada diferença significativa entre as amostras de digesta coletadas apenas no período diurno e aquelas coletadas no período diário, portanto, a digestibilidade pode ser estimada com coleta de amostras realizadas apenas no período diurno. Embora a FDNi, a FDAi e o Co-FDAi possam ser utilizados na estimativa de parâmetros de digestibilidade parcial na coleta de digesta omasal, recomenda-se o uso das fibras indigestíveis por serem menos onerosas e de melhor manipulação.

Palavras-chave: complexo de cobalto-ácido etilenodiaminotetracético, fibra em detergente ácido indigestível, fibra em detergente neutro indigestível, omaso, óxido crômico, período de coleta

\section{Markers for measurements of partial digestion in cattle}

\begin{abstract}
The objective of this trial was to investigate the intestinal digestion of neutral detergent fiber (NDF) using different markers and the effect of sampling collection period (daytime vs. diurnal) on nutrient digestion. Four crossbred Holstein x Zebu heifers fitted with ruminal and ileal cannulas were used in this trial. Animals were housed in individual pens and fed ad libitum bermudagrass hay plus $1 \mathrm{~kg}$ of concentrate $(27 \% \mathrm{CP})$. The experiment lasted 60 days with seven days for diet adaptation and four days interval between each of the three 15-days experimental periods. Total fecal collection was done on day 1, 7, and 13, omasal sampling from day 2 to 4 , and ileal digesta collection from day 8 to 10 of each period. Single [indigestible neutral detergent fiber (iNDF), indigestible acid detergent fiber (iADF), and chromium oxide $\left(\mathrm{Cr}_{2} \mathrm{O}_{3}\right)$ ] and double system markers [Co-EDTA plus iNDF (Co-iNDF) and Co-EDTA plus iADF (Co-iADF) were used to measure flow of omasal digesta. Only single markers were used to determine ileal digesta flow. No significant difference was observed on partial nutrient digestibility comparing samples collected during the daytime with those collected during a 24-h period (diurnal) suggesting that samples may be collect only during the daytime. Although iNDF, iADF and Co-iADF can all be used to estimate partial digestion of nutrients flowing past the omasum, it is recommended the use of internal markers (iNDF or iADF) because of low costs and simple determination.
\end{abstract}

Key Words: cobalt-ethylenediaminotetracetic-acid (Co-EDTA) complex, indigestible acid detergent fiber, indigestible neutral detergent fiber, omasum, chromium oxide, collection period 


\section{Introdução}

Mensurações da quantidade e da composição da digesta que passa em diferentes pontos do trato gastrintestinal são informações importantes para predizer a absorção líquida de nutrientes em diferentes segmentos do trato gastrintestinal (France \& Siddons, 1986). Por outro lado, o processo de digestão nos ruminantes é resultado de uma seqüência de eventos em diferentes segmentos do trato gastrintestinal. O local de digestão influencia a natureza dos produtos finais absorvidos, a extensão com que ocorrem as perdas e, provavelmente, a resposta produtiva do animal (Merchen et al., 1997). Desta forma, melhorar a acurácia das técnicas utilizadas para obtenção desses dados reduz o erro na predição de exigências nutricionais (Ahvenjärvi et al., 2003)e torna mais eficiente a utilização dos nutrientes pelos animais, melhorando, conseqüentemente, o desempenho animal.

Nos estudos de digestão, é necessária a utilização de indicadores para estimativa do fluxo de digesta. Os indicadores fornecem uma série de informações relevantes nos estudos de nutrição: a quantidade ingerida de alimentos ou nutrientes específicos; a taxa de passagem da digesta por todo ou parte do trato digestivo e a digestibilidade do alimento ou de nutrientes específicos. Esta técnica baseia-se no princípio de que, se uma substância de referência (indicador) é indigestível, deve ser totalmente recuperada nas fezes ou em algum segmento do trato gastrintestinal.

Muitos estudos têm sido feitos sobre a utilização de indicadores para estimativa da digestibilidade, mas, até o momento, não foi encontrada uma substância com características de indicador perfeito nem definido um componente químico que se assemelhe às características desejadas. Segundo Merchen (1993), nenhuma das substâncias usadas como indicador atende a todas as características, mas várias são adequadas para fornecer dados significativos. Por isso, a procura por melhores indicadores constitui um dos assuntos de grande interesse na pesquisa de técnicas que facilitem estudos de nutrição animal.

Nos últimos anos, foram propostas várias substâncias ou novos métodos de análises que superariam algumas das limitações anteriores (Piaggio et al., 1991). Atualmente, pode-se optar por indicadores internos, que ocorrem naturalmente nos alimentos, ou por indicadores externos, adicionados às dietas ou infundidos via cânulas.

Dos indicadores externos, o mais utilizado é o óxido crômico, entretanto, apresenta grande variação de resultados (Freitas et al., 2002). O uso deste indicador é estimulado principalmente pelo fato de ser menos oneroso, ser facilmente incorporado à dieta e analisado com relativa facilidade (Merchen, 1993).
Entre os indicadores internos, as fibras indigestíveis são os mais utilizados. Segundo Cochran et al. (1986), a fibra em detergente neutro indigestível (FDNi) e a fibra em detergente ácido indigestível (FDAi) são indicadores com potencial de utilização para estimativa da digestibilidade. Esses indicadores apresentam a vantagem de serem obtidos de modo mais simples e econômico.

Quando se utiliza apenas um indicador, normalmente assume-se que o fluxo da digesta é independente de suas fases e que a amostra é representativa. No caso da técnica de coleta de digesta omasal, as amostras podem não ser representativas da digesta que está deixando o rúmen e passando para o omaso (Huhtanen et al., 1997; Ahvenjärvi et al., 2000).

Erros na estimativa da digestibilidade estão relacionados a problemas na coleta de amostra, ao fato de estas amostras não serem representativas ou ao uso incorreto de indicadores. Para evitar amostragem não-representativa de digesta, a infusão do indicador deve ser feita em todo o rúmen e a digesta ser separada em diferentes fases e, então, reconstituída matematicamente (Owens \& Hanson, 1992). Entretanto, vale ressaltar que ainda são poucos os trabalhos sobre esse assunto e que informações que confirmem esta premissa em condições tropicais são ainda escassas.

De acordo com France \& Siddons (1986), a digesta apresenta uma fase líquida (líquido e pequenas partículas) e outra sólida (médias e grandes partículas), o que possibilita a utilização de dois diferentes indicadores considerados ideais para cada fase. Bons resultados têm sido obtidos com a utilização do Co-EDTA na fase líquida (Ahvenjärvi et al., 2003). Na fase sólida, podem-se empregar indicadores como as fibras indigestíveis (FDAi e FDNi). Como indicador único, podem-se sugerir as fibras indigestíveis ou o $\mathrm{Cr}_{2} \mathrm{O}_{3}$, entretanto, são necessárias mais pesquisas sobre a escolha de indicadores e a definição de um ou mais indicadores.

Desta forma, ao realizar este trabalho, objetivou-se avaliar a digestibilidade intestinal da FDN estimada por diferentes indicadores e o efeito do período de coleta sobre a digestibilidade parcial desse nutriente.

\section{Material e Métodos}

O experimento foi conduzido no Departamento de Zootecnia do Centro de Ciências Agrárias da Universidade Federal de Viçosa, em Viçosa, Minas Gerais, e as análises laboratorias, no Laboratório de Nutrição Animal do mesmo local. Foram utilizadas quatro novilhas mestiças HolandêsZebu, fistuladas no rúmen e no íleo, com $220 \mathrm{~kg}$ de PV inicial e 12 meses de idade, mantidas em baias individuais de 
alvenaria de $3 \mathrm{~m}^{2}$, cobertas, com pisos recobertos com borracha, dotadas de bebedouros automáticos e comedouros.

$\mathrm{O}$ arraçoamento foi realizado duas vezes ao dia (às $8 \mathrm{e}$ 16h) com dieta composta de feno de capim-tifton (Cynodon spp.) oferecido ad libitum e $1 \mathrm{~kg}$ de concentrado. As proporções dos ingredientes do concentrado são apresentadas na Tabela 1 e a composição química dos alimentos, na Tabela 2.

O experimento teve duração de 60 dias, divididos em três períodos de 15 dias. Antes do primeiro período experimental, foi realizada a adaptação dos animais à dieta experimental por sete dias e, entre os períodos, respeitou-se intervalo de quatro dias. As pesagens dos animais foram realizadas ao início e término de cada período experimental.

Tabela 1 - Proporção dos ingredientes do concentrado (\% da MS)

Table 1 - Ingredient composition of the concentrate (\% of DM)

\begin{tabular}{lr}
\hline $\begin{array}{l}\text { Ingrediente } \\
\text { Ingredient }\end{array}$ & MS (\%) \\
Farelo de soja (Soybean meal) & DM) \\
Fubá de milho (Ground corn) & 46,20 \\
Sal (Salt) & 47,99 \\
Fosfato bicálcio (Dicalcium phosphate) & 1,22 \\
Calcário (Limestone) & 2,47 \\
Sulfato de amônia (Ammonium sulphate) & 1,45 \\
Cloreto de potássio (Potassium chloride) & 0,15 \\
Premix mineral (Mineral premix) & 0,44 \\
\hline
\end{tabular}

1 Sulfato de zinco (zinc sulphate): 82,24\%; sulfato de cobre (copper sulphate): $16,45 \%$; sulfato de cobalto (cobalt sulphat): $0,99 \%$ e selenito de sódio (sodium selenite): 0,33 .

Tabela 2 - Composição química dos alimentos e do concentrado (\% da MS)

Table 2 - Chemical composition of dietary feeds and concentrate (\% of DM)

\begin{tabular}{lcccc}
\hline & $\begin{array}{c}\text { Feno de } \\
\text { capim-tifton } \\
\text { Bermudagrass } \\
\text { hay }\end{array}$ & $\begin{array}{c}\text { Fubá de } \\
\text { milho } \\
\text { Ground } \\
\text { corn }\end{array}$ & $\begin{array}{c}\text { Farelo de } \\
\text { soja } \\
\text { Soybean } \\
\text { meal }\end{array}$ & $\begin{array}{c}\text { Concentrado } \\
\text { Concentrate }\end{array}$ \\
\hline MS (DM) & 80,38 & 84,82 & 85,64 & 85,96 \\
MO (OM) & 93,98 & 99,12 & 93,48 & 90,75 \\
PB (CP) & 12,61 & 8,23 & 50,27 & 27,17 \\
EE $($ EE & 2,05 & 4,01 & 1,22 & 2,49 \\
CT $(C H O)$ & 79,32 & 86,88 & 41,99 & 61,09 \\
FDNcp $(N D F a p)^{1}$ & 76,12 & 37,03 & 18,33 & 26,24 \\
CNF $(N F C)$ & 3,20 & 49,85 & 23,66 & 34,85 \\
FDA $($ ADF $)$ & 50,88 & 18,59 & 16,96 & 21,38 \\
FDNi $(\text { iNDF })^{2}$ & 31,66 & 2,48 & 1,88 & 2,06 \\
FDAi $(\text { iADF })^{3}$ & 14,75 & 0,59 & 0,69 & 0,60 \\
\hline
\end{tabular}

${ }^{1} \mathrm{FDNcp}=$ fibra em detergente ácido corrigida para cinzas e proteína (NDFap = neutral detergent fiber corrected for ash and protein).

${ }^{2} \mathrm{FDNi}=$ fibra em detergente neutro indigestível (iNDF $=$ indigestible neutral detergent fiber).

${ }^{3} \mathrm{FDA} \mathrm{i}=$ fibra em detergente ácido indigestível $(i A D F=$ indigestible acid detergent fiber).
Em cada período experimental, realizaram-se as seguintes atividades: coleta total de fezes ( 1 으, $7 \underline{0}$ e 13 o dia); coleta de digesta omasal ( $22^{\circ}$ ao $4 \underline{0}$ dia); coleta de digesta ileal ( $8 \underline{\circ}$ ao 10 - dia); mensuração do $\mathrm{pH}$ ruminal e coleta de amostras spot de urina e líquido ruminal (140 dia) e coleta de líquido ruminal para isolamento bacteriano (15- $\mathrm{dia})$.

Para mensuração do fluxo de digesta omasal, foram utilizados os sistemas único e duplo de indicadores. No sistema único, foram comparados a fibra em detergente neutro indigestível (FDNi), a fibra em detergente ácido indigestível (FDAi) e o óxido crômico $\left(\mathrm{Cr}_{2} \mathrm{O}_{3}\right)$. No sistema duplo, foram comparadas as associações entre o complexo de cobalto-ácido etilenodiaminotetracético (Co-EDTA) para a fase líquida com a FDNi (Co-FDNi) e a FDAi (Co-FDAi) para a fase sólida. Para o fluxo ileal, foram comparados apenas os indicadores únicos.

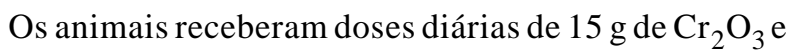
$16 \mathrm{~g}$ de Co-EDTA. $\mathrm{O} \mathrm{Cr}_{2} \mathrm{O}_{3}$ foi acondicionado em cartuchos de papel e colocado, via fístula, diretamente no rúmen quatro horas após o arraçoamento matinal, durante todo o período experimental. O Co-EDTA foi produzido conforme procedimentos de Úden et al. (1980) e diluído em água para infusão, via fístula, em vários locais do rúmen. A administração foi realizada a cada período experimental, cinco dias antes do início da coleta de digesta omasal e até seu término, em quatro doses de $4 \mathrm{~g}$, em intervalos de seis horas, com início duas horas antes do arraçoamento matinal.

Foram coletadas amostras dos alimentos para posteriores análises bromatológicas e, todos os dias antes do arraçoamento matinal, amostras de sobras. Imediatamente após a coleta das sobras, foi feita a pré-secagem em estufa de ventilação forçada a $60^{\circ} \mathrm{C}$ durante 72 a 96 horas. Depois de secas e moídas, as amostras foram compostas proporcionalmente, com base no peso seco ao ar, por animal e por período antes de serem armazenadas.

A coleta total de fezes foi realizada durante 24 horas, com início imediatamente antes do arraçoamento matinal. A cada seis horas, as fezes de cada animal obtidas pela defecação espontânea, foram pesadas, homogeneizadas e amostradas (10\% do peso em matéria natural). Após o período de coleta, foi quantificada a produção fecal total, pela soma das quatro pesagens, e feita amostra composta das quatro subamostras.

As coletas de digestas (omasal e ileal) foram feitas da seguinte forma: no primeiro dia, foram feitas antes ( 0 hora) e 6,12 e 18 horas após o arraçoamento matinal. No segundo dia, foram feitas às $2,8,14$ e 20 horas após o arraçoamento e, no terceiro dia, às 4, 10, 16 e 22 horas após o arraçoamento matinal, totalizando 24 horas de coleta de digesta em intervalos de duas horas. 
Para a coleta de amostras de digesta omasal, foi utilizado um conjunto de dispositivos composto de um kitassato, um tubo coletor e uma bomba a vácuo, conforme técnica descrita por Leão (2002). As amostras de digesta ileal foram coletadas em sacos plásticos adaptados na extremidade do tubo da cânula até que a digesta fluísse normalmente.

As amostras de digestas (omasal e ileal) foram congeladas $\left(-20^{\circ} \mathrm{C}\right) \operatorname{logo}$ após a coleta até serem processadas. Para a digesta omasal, após descongelamento, foi feita amostra composta por animal, por período de coleta (diurno e noturno) e por período experimental. As coletas do período diurno foram realizadas nos tempos $0,2,4,6,8 \mathrm{e}$ $10 \mathrm{~h}$ e as do período noturno, nos tempos 12, 14, 16, 18, 20 e $22 \mathrm{~h}$. Depois de feitas as amostras compostas, parte foi filtrada em camada de tecido de algodão, separando a amostra em duas fases: o líquido filtrado constituiu a fase líquida e o resíduo retido, a fase sólida da digesta omasal. A amostra que não foi filtrada constituiu a digesta total.

O filtrado omasal (fase líquida), o resíduo omasal retido (fase sólida), a digesta omasal total e as amostras de digesta ileal foram submetidos à pré-secagem em estufa de ventilação forçada a $60^{\circ} \mathrm{C}$, durante 72 a 96 horas. Logo depois, foram moídas e armazenadas em frascos para posteriores análises laboratoriais. Nas amostras de digesta ileal, foi feita uma amostra composta por animal, por período de coleta (diurno e noturno) e por período experimental. Para o preparo da amostra composta por período de coleta, foram considerados os mesmos tempos utilizados nas amostras de digesta omasal.

As amostras totais de digesta omasal e de digesta ileal foram analisadas quanto ao teor de cromo em espectrofotômetro de absorção atômica, conforme método descrito por Willians et al. (1962). As amostras dos alimentos, das sobras, da digesta omasal total e das fases sólida omasal e ileal foram submetidas às análises de FDNi e FDAi em sacos de Ankon (filter bags F57) pela incubação in situ por 240 horas (Lippke et al., 1986) em uma vaca Holandesa fistulada no rúmen alimentada com dieta à base de silagem de milho. As amostras de fase líquida e sólida omasal foram preparadas para análise de cobalto em espectrofotômetro de absorção atômica.

Todas as amostras foram analisadas quanto aos teores de MS, conforme técnica descrita por Silva \& Queiroz (2002), e FDN, pela técnica da autoclavagem (Pell \& Schofield, 1993). No resíduo da FDN, foram estimados os teores de cinza e proteína, segundo procedimentos descritos por Silva \& Queiroz (2002), para a obtenção da FDN corrigida para cinzas e proteína (FDNcp).

O fluxo de MS e de FDNcp nas amostras totais de digesta omasal e ileal foi estimado com o uso de indicador único $\left(\mathrm{Cr}_{2} \mathrm{O}_{3}\right.$, FDNi e FDAi), conforme equação de France $\&$ Siddons (1986):

\section{Dose do indicador (mg/dia) \\ $\overline{\text { Concentração do indicador (mg/g digestão) }}$}

Para o cálculo do fluxo omasal com duplo indicador, consideraram-se os indicadores da fase sólida (FDNi e FDAi), ideais, e o da fase líquida (Co-EDTA), não-ideal, segundo a equação (France \& Siddons, 1986): $\left(\mathrm{I}_{\mathrm{L}} / \mathrm{C}_{\mathrm{L}}\right)+\left(\mathrm{I}_{\mathrm{S}} /\right.$ $\mathrm{C}_{\mathrm{S}}$ ), em que $\mathrm{I}_{\mathrm{L}}$ é a dose do indicador líquido (Co-EDTA) administrado (mg/dia) menos a quantidade presente na digesta omasal de fase sólida (mg); $\mathrm{C}_{\mathrm{L}}$, a concentração de Co-EDTA (mg/g de digesta omasal de fase líquida); $\mathrm{I}_{S}$, a dose do indicador sólido (FDNi ou FDAi) em mg/g de digesta omasal de fase sólida; e $\mathrm{C}_{\mathrm{S}}$, a concentração do indicador sólido ( $\mathrm{mg} / \mathrm{g}$ de digesta omasal de fase sólida).

Os valores das estimativas dos fluxos omasal e ileal e da digestibilidade intestinal da FDNcp do período diurno incluíram os resultados das amostras do período diurno e os valores do período noturno, a média das estimativas dos períodos diurno e noturno.

Os dados foram analisados de forma independente para cada indicador ou pela combinação de indicadores, segundo o modelo:

$$
Y_{i j k}=\mu+A_{i}+P_{j}+e_{i j}+C_{k}+\varepsilon_{i j k}
$$

em que $Y_{i j k}=$ observação da variável referente ao animal $i$, no período $\mathrm{j}$ e no esquema de coleta $\mathrm{k} ; \mu=$ constante geral; $\mathrm{A}_{\mathrm{i}}=$ efeito relacionado ao animal $\mathrm{i} ; \mathrm{P}_{\mathrm{j}}=$ efeito relacionado ao período $\mathrm{j} ; \mathrm{e}_{\mathrm{ij}}=$ efeito residual das parcelas experimentais; $\mathrm{C}_{\mathrm{k}}=$ efeito relacionado ao esquema de coleta $\mathrm{k}$; e $\varepsilon_{\mathrm{ijk}}=$ erro aleatório associado a cada observação, pressuposto NID $\left(0 ; \sigma^{2}\right)$.

Todas as análises estatísticas foram realizadas por meio do programa Statistical Analysis System (SAS, 1999), adotando-se nível de significância de 5\%. A comparação entre indicadores ou combinação de indicadores foi realizada pelo intervalo de confiança, considerando como critério de igualdade a observação de sobreposição dos intervalos.

Diante do pressuposto teórico de digestibilidade nula do FDNcp no intestino delgado, os indicadores ou a combinação de indicadores que continham o valor paramétrico zero em seus respectivos intervalos de confiança para este parâmetro foram considerados exatos como estimadores do coeficiente de digestibilidade intestinal.

\section{Resultados e Discussão}

As médias do fluxo de FDNcp, em função dos períodos de coleta e dos indicadores avaliados, podem ser observadas na Tabela 3. Não houve diferenças significativas $(P>0,05)$ 
dos valores de fluxo na coleta de amostras realizadas no período diurno ou diário, tanto para o fluxo omasal quanto para o ileal. Isso pode ser explicado, em parte, pelo fato de a taxa de passagem ruminal e o fluxo de digesta foram aproximadamente constantes para o intestino delgado. Esse resultado está de acordo com os observados por Tibo et al. (2000), ao estudarem as digestibilidades parcial e total nos períodos diurno e noturno. Estes autores não constataram diferenças significativas entre os períodos de coleta das amostras e afirmaram que a realização de coletas somente durante o dia seria suficiente para obtenção de amostras representativas das fezes e das digestas de abomaso e íleo.

Considerando os desvios-padrão do fluxo omasal, os indicadores duplos foram mais precisos quando comparados aos únicos. Na análise individual de cada indicador, o Co-FDAi apresentou a maior precisão e a FDNi, a menor. Analisando os desvios-padrão do fluxo ileal, o $\mathrm{Cr}_{2} \mathrm{O}_{3}$ foi o menos preciso. As fibras indigestíveis apresentaram desvios-padrão próximos. O resultado da menor precisão do $\mathrm{Cr}_{2} \mathrm{O}_{3}$ em comparação aos outros indicadores pode ser explicado pelas flutuações cíclicas em sua excreção(Hopper et al., 1978; Prigge et al., 1981), por não se misturar bem na digesta (é um pó extremamente fino e pouco solúvel em água) ou por apresentar características cinéticas distintas da fase

Tabela 3 - Fluxos omasal e ileal ( $\mathrm{kg} / \mathrm{dia})$ de FDN corrigida para cinzas e proteína (FDNcp) em diferentes períodos de coleta

Table 3 - Omasal and ileal ( $\mathrm{kg} /$ day) flows of NDF corrected for ash and protein at different sampling collection periods

\begin{tabular}{|c|c|c|}
\hline & $\begin{array}{l}\text { Período de coleta } \\
\text { Sample collection }\end{array}$ & \\
\hline Indicador ${ }^{1}$ & Diário & Valor-P ${ }^{2}$ Desvio-padrão \\
\hline Marker & Daytime Diurnal & P-Value Standard deviation \\
\hline
\end{tabular}

Omasal

Omasum

\begin{tabular}{lllll}
\hline $\mathrm{Cr}_{2} \mathrm{O}_{3}$ & 1,258 & 1,300 & 0,3368 & 0,097 \\
FDNi (iNDF) & 1,233 & 1,230 & 0,9573 & 0,144 \\
FDAi (iADF) & 1,162 & 1,102 & 0,1751 & 0,098 \\
$\mathrm{Co}-\mathrm{FDNi}(C o-i N D F)$ & 1,384 & 1,390 & 0,6925 & 0,031 \\
$\mathrm{Co}-\mathrm{FDAi}(C o-i A D F)$ & 1,158 & 1,168 & 0,7319 & 0,067 \\
\hline
\end{tabular}

Ileal

Ileum

\begin{tabular}{lllll}
\hline $\mathrm{Cr}_{2} \mathrm{O}_{3}$ & 1,157 & 0,997 & 0,0669 & 0,183 \\
FDNi $_{(i N D F)}$ & 1,214 & 1,224 & 0,7279 & 0,068 \\
FDAi (iADF) & 1,137 & 1,150 & 0,6171 & 0,058
\end{tabular}

${ }^{1} \mathrm{Cr}_{2} \mathrm{O}_{3}=$ óxido crômico (Chromium oxide); $\mathrm{FDNi}$ = fibra em detergente neutro indigestível ( $i N D F=$ indigestible neutral detergent fiber); $F D A i=$ fibra em detergente ácido indigestível ( $A D F=$ indigestible acid detergent fiber); Co-FDNi = complexo de cobalto-ácido etilenodiaminotetracético (Co-EDTA) associado à $\mathrm{FDNi}(\mathrm{Co}-\mathrm{iNDF}=\mathrm{Co}-\mathrm{EDTA}$ plus $i N D F) ; \mathrm{Co}-\mathrm{FDAi}=\mathrm{Co}-\mathrm{EDTA}$ associado à FDAi (Co-iADF= Co-EDTA plus iADF).

2 Nível descritivo de probabilidade para o erro tipo I associado à hipótese de nulidade relacionada à ausência de diferença entre período de coletas pelo teste $\mathrm{F}$ (Descriptive level of probability for type l error associated with the null hypothesis of no difference between sampling collection periods by F test). da digesta a qual se pretende marcar, visto que sua densidade específica é maior que a do alimento (Merchen, 1993).

Os intervalos de confiança (IC) do fluxo de FDNcp omasal e ileal obtidos com os indicadores nos diferentes períodos de coleta são descritos na Tabela 4. Analisando os IC, para o fluxo omasal de FDNcp em função dos períodos de coleta e dos diferentes indicadores e considerando a interposição dos IC como critério de igualdade, ou seja, valores iguais compreendidos entre IC diferentes, o do CoFDNi apresentou maior $(\mathrm{P}<0,05)$ estimativa do fluxo omasal em relação aos outros indicadores, que não diferiram $(\mathrm{P}>0,05)$ entre si. Da mesma forma que no fluxo omasal, não foi observada diferença significativa $(\mathrm{P}>0,05)$ entre os indicadores únicos no fluxo ileal. Ahvenjärvi et al. (2003) também observaram maior precisão dos indicadores duplos em comparação ao único, como verificado neste trabalho. No entanto, o uso dos indicadores únicos $\left(\mathrm{Cr}_{2} \mathrm{O}_{3}\right.$ e $\left.\mathrm{FDNi}\right)$, em relação ao indicador duplo (Co-FDNi), resultou em estimativa maior do fluxo da MO omasal. Entretanto, ao contrário do que foi observado neste experimento, Freitas et al. (2002) verificaram que o $\mathrm{Cr}_{2} \mathrm{O}_{3}$ superestimou o fluxo de $\mathrm{MS}$

Tabela 4 - Limites inferior (LI) e superior (LS) do intervalo de confiança a $95 \%$ de probabilidade para os fluxos omasal e ileal de FDN corrigida para cinzas e proteína da dieta experimental em diferentes períodos de coleta e com diferentes indicadores avaliados

Table 4 - Lower (LL) and upper (UL) limits of 95\% confidence intervals for omasal and ileal flows of NDF corrected for ash and protein at different sampling collection periods and with different marker systems

\begin{tabular}{|c|c|c|c|c|}
\hline \multirow[b]{3}{*}{ Indicador $^{1}$} & \multicolumn{4}{|c|}{$\begin{array}{l}\text { Período de coleta } \\
\text { Sample collection }\end{array}$} \\
\hline & \multicolumn{2}{|c|}{$\begin{array}{l}\text { Diurno } \\
\text { Daytime }\end{array}$} & \multicolumn{2}{|c|}{$\begin{array}{l}\text { Diário } \\
\text { Diurnal }\end{array}$} \\
\hline & LI & LS & LI & LS \\
\hline Marker & $L L$ & $U L$ & $L L$ & $U L$ \\
\hline \multicolumn{5}{|l|}{ Omasal } \\
\hline \multicolumn{5}{|l|}{ Omasum } \\
\hline $\mathrm{Cr}_{2} \mathrm{O}_{3}$ & 1,193 & 1,323 & 1,235 & 1,365 \\
\hline $\mathrm{FDNi}(i N D F)$ & 1,136 & 1,330 & 1,133 & 1,327 \\
\hline FDAi $(i A D F)$ & 1,096 & 1,228 & 1,036 & 1,168 \\
\hline Co-FDNi $(C o-i N D F)$ & 1,363 & 1,405 & 1,369 & 1,411 \\
\hline Co-FDAi $(C o-i A D F)$ & 1,113 & 1,203 & 1,123 & 1,213 \\
\hline \multicolumn{5}{|l|}{ Ileal } \\
\hline \multicolumn{5}{|l|}{ Ileum } \\
\hline $\mathrm{Cr}_{2} \mathrm{O}_{3}$ & 1,034 & 1,280 & 0,874 & 1,120 \\
\hline $\mathrm{FDNi}(i N D F)$ & 1,168 & 1,260 & 1,178 & 1,270 \\
\hline FDAi $(i A D F)$ & 1,098 & 1,176 & 1,111 & 1,189 \\
\hline
\end{tabular}

${ }^{1} \mathrm{Cr}_{2} \mathrm{O}_{3}=$ óxido crômico; $\mathrm{FDNi}$ = fibra em detergente neutro indigestível; FDAi = fibra em detergente ácido indigestível; Co-FDNi = complexo de cobalto-ácido etilenodiaminotetracético (Co-EDTA) associado à FDNi Co-FDAi = Co-EDTA associado à FDAi

${ }^{1} \mathrm{Cr}_{2} \mathrm{O}_{3}=$ chromium oxide; $i N D F=$ indigestible neutral detergent fiber; $i A D F=$ indigestible acid detergent fiber; Co-iNDF $=$ Co-EDTA plus iNDF; Co-iADF = Co-EDTA plus iADF. 
duodenal em relação aos indicadores internos utilizados e a FDNi e a FDAi não diferiam entre si. Ítavo et al. (2002), no entanto, relataram não haver diferenças significativas entre a FDAi e o $\mathrm{Cr}_{2} \mathrm{O}_{3}$ na estimativa de digestibilidade ruminal da MS e sugeriram que a FDAi pode ser utilizada para estimar as digestibilidades parciais.

Os dados sobre as médias de digestibilidade de FDNcp utilizando diferentes combinações de indicadores são apresentados na Tabela 5. Analisando as médias, considerando que o valor deveria ser zero por não haver digestibilidade intestinal de fibras, verifica-se que a combinação FDNi-FDNi resultou em valores mais próximos ao desejável para ambos os períodos de coleta, sugerindo melhor exatidão. As combinações $\mathrm{Cr}_{2} \mathrm{O}_{3}$-FDNi, FDAiFDAi, Co-FDAi- $\mathrm{Cr}_{2} \mathrm{O}_{3}$ e Co-FDAi-FDAi possibilitaram encontrar valores próximos de zero em apenas um período, enquanto as combinações utilizando a FDAi no omaso resultaram em valores negativos. Nos resultados com valores diferentes de zero, as combinações de indicadores não foram eficientes em estimar a digestibilidade intestinal da FDNcp. No entanto, é necessário comparar estatisticamente essas médias para verificar se realmente essas combinações de indicadores não foram exatas, como demonstrado na Tabela 6.

Comparando os períodos de coleta, observou-se que a digestibilidade intestinal da FDNcp, de modo geral, não
$(\mathrm{P}>0,05)$ foi influenciada pelos períodos de coleta. Somente ocorreu diferença $(\mathrm{P}<0,05)$ na estimativa da digestibilidade intestinal da FDNcp quando utilizada a FDAi no omaso e o $\mathrm{Cr}_{2} \mathrm{O}_{3}$ no íleo, o que diferiu dos resultados anteriores, pois, ao analisar os fluxos omasal e ileal, nenhuma diferença foi observada, o que pode ter sido decorrente do baixo LI do IC do $\mathrm{Cr}_{2} \mathrm{O}_{3}$ no fluxo ileal para o período diário (Tabela 4).

$\mathrm{Na}$ análise dos desvios-padrão das combinações de indicadores (Tabela 5), observou-se que as combinações de indicadores iguais possibilitam estimativas mais precisas que a combinação de indicadores diferentes no omaso e no íleo. Assim, comparando as combinações de indicadores, com exceção da combinação do $\mathrm{Cr}_{2} \mathrm{O}_{3}$, a combinação FDNiFDNi,FDAi-FDAi, Co-FDNi-FDNieCo-FDAi-FDAi foi mais precisa que a dos indicadores omasais com o $\mathrm{Cr}_{2} \mathrm{O}_{3}$ como indicador ileal.

Os dados sobre os intervalos de confiança dos coeficientes de digestibilidade de FDNcp utilizando diferentes indicadores são descritos na Tabela 6. Quando comparado o intervalo de confiança, e considerando o pressuposto teórico de digestibilidade nula do FDNcp no intestino delgado, todos os indicadores, à exceção do Co-FDNi, foram exatos em pelo menos uma combinação, pois contiveram o valor paramétrico zero em seus respectivos IC. O uso de Co-FDNi não proporcionou intervalo de confiança que contivesse a digestibilidade intestinal do FDNcp nula pelo

Tabela 5 - Coeficientes de digestibilidade intestinal (\% do total ingerido) de FDN corrigida para cinzas e proteína (FDNcp) estimados por diferentes indicadores usados no omaso e íleo em diferentes períodos de coleta

Table 5 - Coefficients of intestinal digestibility (\% of intake) of NDF corrected for ash and protein using different marker systems and sampling collection periods

\begin{tabular}{|c|c|c|c|c|c|}
\hline \multirow{2}{*}{$\begin{array}{l}\text { Indicador }{ }^{1} \\
\text { Marker } \\
\text { Omaso } \\
\text { Omasum }\end{array}$} & \multirow[b]{2}{*}{$\begin{array}{l}\text { Íleo } \\
\text { Ileum }\end{array}$} & \multicolumn{2}{|c|}{$\begin{array}{l}\text { Período de coleta } \\
\text { Sample collection }\end{array}$} & \multirow[b]{2}{*}{$\begin{array}{c}\text { Valor- } \mathrm{P}^{2} \\
P \text {-Value }\end{array}$} & \multirow[b]{2}{*}{$\begin{array}{l}\text { Desvio-padrão } \\
\text { Standard-deviation }\end{array}$} \\
\hline & & $\begin{array}{l}\text { Diurno } \\
\text { Daytime }\end{array}$ & $\begin{array}{l}\text { Diário } \\
\text { Diurnal }\end{array}$ & & \\
\hline $\mathrm{Cr}_{2} \mathrm{O}_{3}$ & $\begin{array}{l}\mathrm{Cr}_{2} \mathrm{O}_{3} \\
\text { FDNi }(i N D F) \\
\text { FDAi }(i A D F)\end{array}$ & $\begin{array}{l}4,55 \\
2,56 \\
5,37\end{array}$ & $\begin{array}{l}7,50 \\
0,46 \\
3,05\end{array}$ & $\begin{array}{l}0,2517 \\
0,0902 \\
0,2095\end{array}$ & $\begin{array}{l}0,057 \\
0,026 \\
0,041\end{array}$ \\
\hline $\begin{array}{ll}\mathrm{FDNi} & (i N D F) \\
\mathrm{FDNi} & (i N D F)\end{array}$ & $\mathrm{Cr}_{2} \mathrm{O}_{3}$ & $\begin{array}{l}2,23 \\
0,24\end{array}$ & $\begin{array}{l}7,22 \\
0,17\end{array}$ & $\begin{array}{l}0,0708 \\
0,9720\end{array}$ & $\begin{array}{l}0,058 \\
0,045\end{array}$ \\
\hline FDAi $(i A D F)$ & $\begin{array}{l}\mathrm{Cr}_{2} \mathrm{O}_{3} \\
\text { FDAi }(i A D F)\end{array}$ & $\begin{array}{l}-2,95 \\
-2,14\end{array}$ & $\begin{array}{r}4,13 \\
-0,33\end{array}$ & $\begin{array}{l}0,0379 \\
0,2829\end{array}$ & $\begin{array}{l}0,069 \\
0,037\end{array}$ \\
\hline Co-FDNi (Co-iNDF) & $\begin{array}{l}\mathrm{Cr}_{2} \mathrm{O}_{3} \\
\mathrm{FDNi}_{(i N D F)}\end{array}$ & $\begin{array}{l}8,61 \\
6,62\end{array}$ & $\begin{array}{r}13,14 \\
6,09\end{array}$ & $\begin{array}{l}0,1044 \\
0,5841\end{array}$ & $\begin{array}{l}0,059 \\
0,022\end{array}$ \\
\hline Co-FDAi $(C o-i A D F)$ & $\begin{array}{l}\mathrm{Cr}_{2} \mathrm{O}_{3} \\
\text { FDAi }(i A D F)\end{array}$ & $\begin{array}{l}0,37 \\
1,19\end{array}$ & $\begin{array}{l}4,56 \\
0,11\end{array}$ & $\begin{array}{l}0,1876 \\
0,4657\end{array}$ & $\begin{array}{l}0,070 \\
0,033\end{array}$ \\
\hline
\end{tabular}

${ }^{1} \mathrm{Cr}_{2} \mathrm{O}_{3}=$ óxido crômico; $\mathrm{FDNi}$ = fibra em detergente neutro indigestível; FDAi = fibra em detergente ácido indigestível; Co-FDNi = complexo de cobaltoácido etilenodiaminotetracético (Co-EDTA) associado à FDNi; Co-FDAi = Co-EDTA associado à FDAi.

2 Nível descritivo de probabilidade para o erro tipo I associado à hipótese de nulidade relacionada à ausência de diferença entre período de coletas pelo teste $F$.

${ }_{1} \mathrm{Cr}_{2} \mathrm{O}_{3}=$ chromium oxide; iNDF = indigestible neutral ldetergent fiber; $i A D F=$ indigestible acid detergent fiber; Co-iNDF=Co-EDTA plus iNDF; Co-iADF=Co-EDTA plus iADF.

2 Descriptive level of probability for type l error associated with the null hypothesis of no difference between sampling collection periods by $F$ test). 
Tabela 6 - Limites inferior (LI) e superior (LS) do intervalo de confiança a 95\% de probabilidade para os coeficientes de digestibilidade intestinal (\% do total ingerido) de FDN corrigida para cinzas e proteína (FDNcp) estimados por diferentes indicadores usados no omaso e íleo em diferentes períodos de coleta

Table 6 - Lower (LL) and upper (UL) limits of 95\% confidence intervals for the coefficients of intestinal digestibility (\% of intake) of NDF corrected for ash and protein using different marker systems and sampling collection periods

\begin{tabular}{|c|c|c|c|c|c|}
\hline \multicolumn{2}{|c|}{$\begin{array}{l}\text { Indicador }^{1} \\
\text { Marker }\end{array}$} & \multicolumn{4}{|c|}{$\begin{array}{l}\text { Período de coleta } \\
\text { Sample collection }\end{array}$} \\
\hline \multirow{4}{*}{$\begin{array}{l}\text { Omaso } \\
\text { Omasum }\end{array}$} & \multirow{4}{*}{$\begin{array}{l}\text { Íleo } \\
\text { Ileum }\end{array}$} & \multirow{2}{*}{\multicolumn{2}{|c|}{$\begin{array}{l}\text { Diurno } \\
\text { Daytime }\end{array}$}} & \multirow{2}{*}{\multicolumn{2}{|c|}{$\begin{array}{l}\text { Diário } \\
\text { Diurnal }\end{array}$}} \\
\hline & & & & & \\
\hline & & LI & LS & LI & LS \\
\hline & & $L L$ & $U L$ & $L L$ & $U L$ \\
\hline \multirow{3}{*}{$\mathrm{Cr}_{2} \mathrm{O}_{3}$} & $\mathrm{Cr}_{2} \mathrm{O}_{3}$ & 0,71 & 8,39 & 3,66 & 11,34 \\
\hline & $\mathrm{FDNi}(i N D F)$ & 0,79 & 4,33 & $-1,31$ & 2,23 \\
\hline & FDAi $(i A D F)$ & 2,64 & 8,10 & 0,32 & 5,78 \\
\hline \multirow[t]{2}{*}{ FDNi $(i N D F)$} & $\mathrm{Cr}_{2} \mathrm{O}_{3}$ & $-1,66$ & 9,26 & 3,33 & 11,11 \\
\hline & FDNi $(i N D F)$ & $-2,78$ & 3,26 & $-2,85$ & 3,19 \\
\hline \multirow[t]{2}{*}{ FDAi $(i A D F)$} & $\mathrm{Cr}_{2} \mathrm{O}_{3}$ & $-7,61$ & 2,52 & $-0,53$ & 8,79 \\
\hline & FDAi $(i A D F)$ & $-4,65$ & 0,37 & $-2,84$ & 2,18 \\
\hline \multirow[t]{2}{*}{ Co-FDNi $(C o-i N D F)$} & $\mathrm{Cr}_{2} \mathrm{O}_{3}$ & 4,61 & 12,61 & 9,14 & 17,14 \\
\hline & $\mathrm{FDNi}(i N D F)$ & 5,14 & 8,10 & 4,61 & 7,57 \\
\hline \multirow[t]{2}{*}{ Co-FDAi $(C o-i A D F)$} & $\mathrm{Cr}_{2} \mathrm{O}_{3}$ & $-4,31$ & 5,05 & $-0,12$ & 9,24 \\
\hline & FDAi $(i A D F)$ & $-1,06$ & 3,44 & $-2,14$ & 2,36 \\
\hline
\end{tabular}

${ }^{1} \mathrm{Cr}_{2} \mathrm{O}_{3}=$ óxido crômico; FDNi = fibra em detergente neutro indigestível; FDAi = fibra em detergente ácido indigestível; Co-FDNi = complexo de cobaltoácido etilenodiaminotetracético (Co-EDTA) associado à FDNi; Co-FDAi = Co-EDTA associado à FDAi.

${ }_{1}^{1} \mathrm{Cr}_{2} \mathrm{O}_{3}=$ chromium oxide; iNDF = indigestible neutral detergent fiber; iADF = indigestible acid detergent fiber; Co-iNDF=Co-EDTA plus iNDF; Co-iADF =Co-EDTA plus iADF.

fato de o fluxo omasal ter sido superestimado (Tabela 3 ) em relação aos demais indicadores. Uma explicação para esta diferença é que o indicador pode não ter resultado em amostra representativa da digesta omasal.

$\mathrm{O}$ uso do $\mathrm{Cr}_{2} \mathrm{O}_{3}$ como indicador omasal, por ter apresentado exatidão somente quando combinado com FDNi ileal nas amostras de 24 horas, tem sua precisão passível de questionamentos. Em outros trabalhos, a utilização do $\mathrm{Cr}_{2} \mathrm{O}_{3}$ não foi satisfatória (Oliveira et al., 2001; Santos et al., 2001; Imaizumi et al., 2002; Oliveira Jr. et al., 2002; Rabelo, 2002), pois não foram atingidas recuperações satisfatórias de cromo e os coeficientes de digestibilidade foram baixos ou até negativos, o que, possivelmente, decorreu das maiores variações na concentração de cromo que na FDNi na digesta (Ahvenjärvi et al., 2001) e de problemas na técnica de determinação de sua concentração nas amostras.

Detmann et al. (2005), ao analisarem a estabilidade do perfil excretório dos indicadores internos (MSi, FDNi e FDAi) em relação ao comportamento comumente descrito para o $\mathrm{Cr}_{2} \mathrm{O}_{3}$, observaram maior estabilidade nos indicadores internos, fato justificado pelas diferenças na dosagem desses indicadores nos animais. Enquanto o $\mathrm{Cr}_{2} \mathrm{O}_{3}$ é comumente introduzido no rúmen em uma ou duas doses diárias, os indicadores internos apresentam dosagem homogênea, coincidente ao consumo de alimentos, que pode ser realizado continuamente e constantemente caso as condições de alimentação sejam mantidas estáveis qualitativa e quantitativamente (Detmann et al., 2005).

Considerando os limites do IC dos diferentes tratamentos (Tabela 6) e que as comparações de IC equivalem a teste de médias, ao traçar retas desses IC, observou-se sobreposição dos intervalos de confiança, ou seja, valores iguais. Assim, o uso de indicador único ou duplo não diferiu ( $\mathrm{P}>0,05)$, o que está de acordo com observações de Lundy et al. (2004), que encontraram digestibilidade da MS e da FDN similares às observadas por Reynal \& Broderick (2003), utilizando apenas o $\mathrm{Cr}_{2} \mathrm{O}_{3}$ como indicador omasal em vez do indicador triplo combinando Co-EDTA, cloreto de itérbio e FDAi.

Analisando o comprimento dos IC das diferentes combinações de indicadores consideradas exatas, excetuando a utilização de $\mathrm{Cr}_{2} \mathrm{O}_{3}$ na digesta omasal, os menores valores foram observados na digesta total com combinações de indicadores iguais no omaso e no íleo (FDNi-FDNi, FDAIFDAI), na digesta omasal com duas fases utilizando indicadores iguais na fase sólida e na digesta ileal (Co-FDAiFDAI). Esses IC apresentaram comprimento médio de 5,19, enquanto os demais ( $\mathrm{FDNi}-\mathrm{Cr}_{2} \mathrm{O}_{3}$, FDAi- $\mathrm{Cr}_{2} \mathrm{O}_{3}$ e Co-FDAi$\mathrm{Cr}_{2} \mathrm{O}_{3}$ ) foram 9,82, o que sugere melhor precisão para os indicadores iguais, tendo em vista o menor comprimento de 
IC e, conseqüentemente, a menor variação dos dados, confirmando os resultados observados na Tabela 5 pela comparação dos desvios-padrão.

Como os resultados obtidos com o uso do indicador duplo no omaso foram similares aos obtidos com o uso de indicador único, recomenda-se o uso de apenas um indicador único, em virtude de seu menor custo e de sua praticidade. Considerando a menor praticidade e precisão (Tabela 5) no uso simultâneo de indicadores diferentes no omaso e no íleo e que as fibras indigestíveis estão contidas no alimento, é preferível o uso simultâneo de FDNi ou FDAi no omaso e no íleo para estimar a digestibilidade.

Pereira (2003), ao estudar a FDAi, recomendou a utilização deste indicador para estimativa do fluxo de MS omasal e fecal. Freitas et al. (2002) concluíram que a FDAi e o $\mathrm{Cr}_{2} \mathrm{O}_{3}$ podem ser utilizados na estimativa da produção fecal, no entanto, recomendaram a utilização da FDAi por sua obtenção ser mais simples e econômica. Como neste experimento, esses autores também verificaram que os indicadores internos FDAi e FDNi mostraram-se adequados.

\section{Conclusões}

Na estimativa da digestibilidade, podem ser utilizadas amostras de digesta coletada apenas no período diurno, pois essas amostras não diferem daquelas coletadas no período diário.

A FDNi, a FDAi e o Co-FDAi podem ser utilizados como indicadores para estimativa de parâmetros de digestibilidade parcial na coleta de digesta omasal, porém, recomenda-se o uso das fibras indigestíveis por serem menos onerosas e de mais fácil manipulação.

\section{Literatura Citada}

AHVENJÄRVI, S.; VANHATALO, A.; HUHTANEN, P. et al Determination of reticule-rumen and whole-stomach digestion in lactating cows by omasal canal or duodenal sampling. British Journal of Nutrition, v.83, n.1, p.67-77, 2000 .

AHVENJÄRVI, S.; SKIBA, B.; HUHTANEN, P. Effect heterogeneous digesta chemical composition on the accuracy of measurements of fiber flow in dairy cows. Journal of Animal Science, v.79, n.6, p.1611-1620, 2001.

AHVENJÄRVI, S.; VANHATALO, A.; SHINGFIELD, K.J. et al. Determination of digesta flow entering the omasal canal of dairy cows using different marker systems. British Journal of Nutrition, v.90, n.1, p.41-52, 2003.

COCHRAN, R.C.; ADAMS, D.C.; WALLACE, J.D. et al. Predicting digestibility of different diets with internal markers: evaluation of four potential markers. Journal of Animal Science, v.63, n.5, p.1476-1483, 1986.

DETMANN, E.; BARROS, E.E.L.; FONTES, C.A.A. et al. Avaliação do perfil nictemeral de excreção de indicadores internos em ensaio de digestão com bovinos. In: REUNIÃO ANUAL DA SOCIEDADE BRASILEIRA DE ZOOTECNIA, 42., 2005, Goiânia. Anais... Goiânia: Macromedia, 2005. (CD-ROM).
FRANCE; J.; SIDDONS, R.C. Determination of digesta flow by continuous marker infusion. Journal of Theoretical Biology, v.121, n.2, p.105-119, 1986.

FREITAS, D.; BERCHIELLI, T.T.; SILVEIRA, R.N. Consumo e digestibilidade aparente total e parcial de rações com cana-deaçúcar e raspa de mandioca ensilados com polpa cítrica. Revista Brasileira de Zootecnia, v.31, n.3, p.1531-1542, 2002. (suplemento)

HOPPER, J.T.; HOLLOWAY, J.W.; BUTTS JR., W.T. Animal variation in chromiun sesquioxide excretion patterns of grazing cows. Journal Animal Science, v.46, n.4, p.1098-1102, 1978.

HUHTANEN, P.; BROTZ, P.G.; SATTER, L.D. Omasal sampling technique for assessing fermentative digestion in the forestomach of dairy cows. Journal of Animal Science, v.75, n.5, p.1380-1392, 1997.

IMAIZUMI, H.; SANTOS, F.A.P.; PIRES, A.V. et al. Avaliação de diferentes fontes e teores de proteína degradável no rúmen sobre o desempenho e parâmetros ruminais e sanguíneos de vacas Holandesas em final de lactação. Acta Scientiarum, v.24, n.4, p.1031-1037, 2002.

ÍTAVO, L.C.V.; SILVA, F.F.; FERREIRA, C.C.B. et al. Comparação de indicadores e metodologia de coleta para estimativas de produção fecal e fluxo da digesta em bovinos. Revista Brasileira de Zootecnia, v.31, n.4, p.1833-1839, 2002.

LEÃO, M.I. Metodologias de coletas de digestas omasal e abomasal em novilhos submetidos a três níveis de ingestão: consumo, digestibilidade e produção microbiana. Belo Horizonte: Universidade Federal de Minas Gerais, 2002. 57p. Tese (Doutorado em Zootecnia) - Universidade Federal de Minas Gerais, Escola de Veterinária, 2002

LIPPKE, H.; ELLIS, W.C.; JACOBS, F. Recovery of indigestible fiber from feces of sheep and cattle on forage diets. Journal of Dairy Science, v.69, n.2, p.403-412, 1986.

LUNDY, F;P.; BLOCK, E.; BRIDGES JR., W.C. et al. Ruminal biohydrogenation in Holstein cows fed soybean fatty acids as amides or calcium salts. Journal of Dairy Science, v.87, n.4, p.1038-1046, 2004

MERCHEN, N.R. Digestion, absorption and excretion in ruminantes In: CHURCH, D.C. (Ed.) The ruminant animal digestive physiology and nutrition. 4.ed. Carvallis: O\&B Books, 1993. p.172-201.

MERCHEN, R.N.; ELIZALDE, J.C.; DRACKLEY, J.K. Current perspective on assessing site of digestion in ruminants. Journal of Animal Science, v.75, n.8, p.2223-2234, 1997

OLIVEIRA, A.S.; VALADARES, R.F.D.; VALADARES FILHO, S.C. et al. Produção de proteína microbiana e estimativas das excreções de derivados de purinas e de uréia em vacas lactantes alimentadas com rações contendo diferentes níveis de compostos nitrogenados não protéicos. Revista Brasileira de Zootecnia, v.30, n.5, p.1621-1629, 2001.

OLIVEIRA JR., R.C.; SUSIN, I.; PIRES, A.V. et al. Desempenho de cabras em lactação alimentadas com grão de soja. Acta Scientiarum, v.24, n.4, p.1113-1118, 2002.

OWENS, F.N.; HANSON, C.F. External and internal markers for appraising site and extent of digestion in ruminants. Journal of Dairy Science, v.75, n.9, p.2605-2617, 1992.

PELL, A.N.; SCHOFIELD, P. Computerized monitoring of gas production to measure forage digestion in vitro. Journal of Dairy Science, v.76, p.1063-1073, 1993.

PEREIRA, M.L.A. Proteína nas dietas de vacas nos terços inicial e médio da lactação. Viçosa, MG: Universidade Federal de Minas Gerais, 2003. 105p. Tese (Doutorado em Zootecnia) - Universidade Federal de Viçosa, 2003.

PIAGGIO, L.M.; PRATES, E.R.; PIRES, F.F. et al. Avaliação das cinzas insolúveis em ácido, fibra detergente ácido indigestível e lignina em detergente ácido indigestível como indicadores internos da digestibilidade. Revista da Sociedade Brasileira de Zootecnia, v.20, n.3, p.306-312, 1991 
PRIGGE, E.C.; VARGA, G.A.; VICINI, J.L. et al. Comparison of ytterbium chloride and chromium sesquioxide as fecal indicators. Journal of Animal Science, v.53, n.6, p.1629-1633, 1981.

RABELO, M.M.A. Efeitos de fontes e níveis de fibra íntegra, em dietas contendo bagaço de cana-de-açúcar tratado sob pressão e vapor, sobre a digestibilidade, desempenho e comportamento ingestivo de bovinos de corte. Piracicaba: Escola Superior de Agricultura "Luiz de Queiroz", 2002. 61p. Dissertação (Mestrado em Ciência Animal e Pastagens) - Escola Superior de Agricultura "Luiz de Queiroz", 2002.

REYNAL, S.M.; BRODERICK, G.A. Effects feeding dairy cows protein supplements of varying ruminal degradability. Journal of Dairy Science, v.86, n.3, p.835-843, 2003

SANTOS, F.A.P.; MENDES JR., M.P.; SIMAS, J.M.C. et al. Processamento do grão de milho e sua substituição parcial por polpa de citros peletizada sobre o desempenho, digestibilidade de nutrientes e parâmetros sangüíneos de vacas leiteiras. Acta Scientiarum, v.23, n.4, p.923-931, 2001.

STATISTICAL ANALYSIS SYSTEM - SAS. SAS/STAT user's guide (Release 8.0). Cary: 1999. (CD-ROM).
SILVA, D.J.; QUEIROZ, A.C. Análises de alimentos: métodos químicos e biológicos. 3.ed. Viçosa, MG: Editora UFV, 2002. $235 \mathrm{p}$.

TIBO, G.C.; VALADARES FILHO, S.C.; VALADARES, R.F.D. et al. Níveis de concentrado em dietas de novilhos mestiços F1 Simental x Nelore. 1. Consumo e digestibilidades. Revista Brasileira de Zootecnia, v.29, n.3, p.910-920, 2000.

ÚDEN, P.; COLUCCI, P.E.; Van SOEST, P.J. Investigation of chromium, cerium and cobalt as markers in digesta. Rate of passage studies. Journal of the Science of Food and Agriculture, v.31, n.7, p.625-632, 1980.

WILLIANS, C.H.; DAVID, D.J.; IISMA, O. The determination of chromic oxide in faeces samples by atomic absorption spectrophotometry. Journal of Agricutural Science, v.59, n.3, p.381-385, 1962.

Recebido: 12/12/05 Aprovado: $14 / 11 / 06$ 